\title{
Artistic Formalism in Relation to Sport
}

\author{
Daniel Shorkend ${ }^{1}$ \\ ${ }^{1}$ Wizo School of Design, Haifa \\ Correspondence: Daniel Shorkend, Wizo School of Design, Haifa
}

Received: January 25, 2019

Accepted: February 18, 2019

Available online: February 20, 2019

doi:10.11114/ijsss.v7i2.4081

URL: https://doi.org/10.11114/ijsss.v7i2.4081

\begin{abstract}
I argue that sport can be considered aesthetic and thus converge with a certain view of art. We can enjoy abundance and proliferation as well as negation and austerity in nature, art and sport. The aesthetics of abundance and negation are "intertwined" in sport as art-like. Sport is well positioned to perform art's cultural task better than traditional forms of art. Art and sport are intertwined in the sense that sport as an aesthetic, cultural phenomenon may continue the work of art. By aesthetics, the author focuses on notions of formalism in sport. This "will to form" is predicated on the need humans have for order, pattern and harmony. In that sense, art and sport might offer us a vision of clarity and precision. A theory of formalism applies equally to art and sport.
\end{abstract}

Keywords: art, sport, formalism, form, intertwining

\section{Introduction}

I propose that sport can be considered aesthetic and thus converge with a certain view of art. By aesthetics, I wish to focus on notions of formalism in sport. If such an argument can be made, then the deduction invoked, namely what I call "the will to form" reasonably involves a valid comparison between "moments" in art and that of sport. My methods are qualitative with the hope that such arguments meet my objectives: what are the overlaps between art and sport when considered formally?

Although there has been arguments concerning the so-named "formalist theory of sport", notably by Edgar (2013), Suits $\left(2014,3^{\mathrm{RD}}\right.$ edition), Kupfer (1975) and James (1963), my contribution is to develop an account of sport that draws from art theory/practice so as to cohere with what has been dubbed the "weak" version of aesthetics of the everyday (Dowling 2010). In this regard, Arnold (1990), Weiss (1969) and Gumbrecht (2006) are useful writers to help argue for a theory of this sort. It should however be made clear that arguing for the overlap between art and sport does not necessarily imply that either art or sport are beautiful as such, for strictly speaking art need not be beautiful and sport may achieve its goals without imputing beauty. I begin then by outlining artistic formalism.

\section{Literature Review}

\subsection{Defining Formalist Theories of Art}

Kant (1952 [1790]) is usually regarded as the founder of formalism, which might equate with aestheticism, though not aesthetics as such (Guyer 1997:80), because formalism is also a kind of ideological stance, rather than simply a general approach to art theory. In this respect, one can only talk of formalism as tending to the aesthetic. Provisionally, one could define formalism as the belief that aesthetic appreciation lies in the pleasure and satisfaction gleaned from the work of art in response to its formal characteristics rather than its subject matter, ideas and content. Kant writes: "beauty is the form of purposiveness of an object" (in Crawford 1974:92). The type of pleasure that this peculiar sensitivity inspires as described by Kant is disinterested passive contemplation. The "aesthetic" viewer is not interested in the use of the object per se, or even in what can be understood by it in terms of a particular cognitive law. Rather, the viewer gains a general pleasure from appreciating the object's aesthetic properties, even if they cannot be described in language.

These "aesthetic properties" entail a search for an artistic ontology reflected in the modernist call for an aesthetic essence as exemplified by the phrase "art for art's sake" and consists of such notions as an aesthetic attitude and contemplation, aesthetic harmony and the belief that significant art is timeless and universal. In order to actualize these ideas, artists tended towards the "purity" and artistic "autonomy" of abstraction, formalist criticism and the universalist conceptions of internationalism. 
Furthermore, such ideas correspond to a belief in an aesthetic essence. Maurice Denis, who is a generation younger that Degas (1834-1917) and who was inspired by the example of Gauguin (1848-1903), wrote the following oft quoted sentence in an essay published in 1890: "Remember that a picture - before being a battle-horse, a nude woman or some anecdote - is essentially a flat surface covered with colours in a certain order" (in Jansen 1967:81). This view transforms the focus of art from its usual representative, expressive functions to a self-awareness and reflexive activity, and thus a certain self-consciousness. This "self-consciousness" is motivated by a search for the essential nature of materials and a revealing of a "depth" lurking beneath formal relationships.

A "depth", an aesthetic harmony pervading art through its formal coherence leads to the modernist "art for art's sake" dictum. It advocates for art a function that is "pure", that is, not simply for use and practical activity, which is in line with Kant's concept of "disinterestedness", and in the process seeks to counter a materialist age and demarcate a separate, pure realm for art, maintaining its distance from the social world. As such, some variants of formalism, tend towards art's own purported spiritual "essence", which is to engage a viewer on the aesthetic level, that is, in terms of a kind of correspondence between inner and outer harmony.

To lend support to formalist theories, that is, that art's value is gleaned from its aesthetic properties, its formal harmony and the like, a theory supporting the nature of visual perception might validate (to a certain degree) the fact that art's significance resides in some basic, intrinsic visual laws that give rise to an aesthetic experience. Rudolf Arnheim (1974:89-90), applying the processes and findings of modern psychology within the realm of human perception, argues that the eye organizes visual material according to definite psychological laws. He describes how the following tools of visual language operate and interact with the perceiving consciousness: balance, shape, form, growth, space, light, colour, movement, dynamics and expression. Art historian, Ernst Gombrich (1960:67) argues that the eye is not a passive instrument, but rather that it serves a mind that is selective if it is not to be swamped by indigestible messages. Arnheim (1974:5) concurs with Gombrich by saying, "All perceiving is also thinking, all reasoning is also intuition, all observation is also invention". Arnheim (1974:93) recounts the same conclusions researchers in art education reached, specifically with regard to "the trust in the objective validity within the visual experience". As an example of this, he cites Gustav Britsch, who successfully proved that the mind works according to logical laws and proceeds from the perceptually simplest components to patterns of increasing complexity (Arnheim 1974:617). Gombrich (1960:65) thus explains that "what an artist constantly worries over whether he or she has got it 'right' is much more difficult to put into words", that is, the concern is with a visual language. Such theories give a certain weight to the claim that the viewer responds to formal patterns over and above its associations and literary content, and that we are hardwired to perceive in a certain way such as is the physiological basis for empathy theories of art. Accordingly, it may not be arbitrary when we value one work over another. Furthermore, if the history of taste is not arbitrary [1], then formal changes follow an evolutionary logic.

In 1936, Alfred Barr, then director of MOMA, published a diagram depicting the evolution of modern art. His ideas reflect the fact that art develops according to its own internal debates and that this debate is simply a matter of form and formal changes. His theory is thus a-political. As such the artwork is an object in its own right, a pictorial reality (Greenberg uses terms such as "...the integrity of the picture plane" [1973:67]), rather than a window into another world, which tends to conceal the illusion, an art of art.

An "art of art", which recalls the "self-consciousness" mentioned above, articulates that art is a specific language that has at its disposal specific tools. The medium is thus not transparent; the form may become the content. This is what led Rozanova (in Harrison \& Wood 1993:202) to make the bold claim that:

only modern art has advocated the full and serious importance of the principles such as pictorial dynamism, volume and equilibrium, weight and weightlessness, linear and plane displacement, rhythm as a legitimate division of space, design, planer and surface dimension, texture, color correlation, and others. Suffice it to enumerate these principles that distinguish the new art from the old to be convinced that they are qualitative - and not just quantitive new basis that moves the self sufficient significance of the new art. They are principles hitherto unknown that signify the rise of a new era in creation - an era of purely artistic achievements

It would seem that formalism is a central theory of much modern art, that is, in particular the abstract art of the early and mid-twentieth century. However, its significance as a theoretical lens can be applied to art generally, as I would claim that formal components are integral to art and many artists wish to induce in the viewer an aesthetic experience so gained by the contemplation of the art object quo form. Braque echoed such a sentiment with the statement that "the aim is not to reconstitute an anecdotal fact but to constitute a pictorial fact" (in Harrison \& Wood 1993:102).

Moreover, formalism is a blanket theory that stretches beyond the visual arts. Sheppard (1987:67) in speaking of music 
[2] also appeals to formal quality like the following description of one classical piece: “...the work opens in C major but then changes into a minor key; the theme introduced by the oboe is taken up by the violins; the rhythms become increasingly syncopated..." Formal features appeal more to knowledgeable audiences. And perhaps with music, of all the arts, formal components are most readily perceived. In ballet too, beauty is conceived in the formal pattern made by the movements of the dancers. In architecture, for example, the Renaissance architect, Palladio modelled his buildings on principles of symmetry. In literature too, we find meter used for verse, ordering of the words, structure of the plot, arrangements of themes of a play are all organized according to specific formal arrangements. The crucial component then is the "body" or form. So, in fact art is but a "playful" surface. Therefore, formalist theories need not be seen as simply a modernist search for "essence" and a deeper, underlying structure or meaning but as an acknowledgement of a kind of aleatory or indeterminism - or creative "play". Or that the aesthetic (visual) sense, following Arnheim, Gombrich and Barr are determined by visual rules (or hard-wiring) over and above what an image represents. We are responding to a "body" as a "body".

Having described a general approach to formalism, I now focus on one such variant of the theory, namely that of Clive Bell. One could sum his ideas briefly as follows:

Bell proposes an aesthetic hypothesis whereby the quality of a work of art is given by significant form. Secondly, significant form is the experience of a peculiar emotion felt for the reality of the artwork. This emotion is an aesthetic emotion which gives rise to a good state of mind. Like Tolstoy's vision, Bell says that art is not something that lives in museums to be understood by the learned alone, rather it is a kind of religion, a refuge from life. This refuge takes place as one is immersed in the pictorial reality of a work of art as Bell (1958:187) aptly puts it: "To appreciate a work of art one brings with us nothing but a sense of form and colour and a knowledge of 3-dimensional space". An extreme denigration of Bell's formalist reductivism is to my mind an ignoring of the significance of the work of art as a work of art. A more moderate perspective, I believe unifies a formalist-aesthetics in art and in its application, or a drawing from art to the beyond (or "other").

Another version of formalism is provided by Clement Greenberg and I would like to highlight some basic insights on the part of Greenberg (1961:73-98) in which he endorsed formalism for the following primary reasons: 1) it was a way of resisting mass culture, 2) it lauded high/fine art and its autonomy and "purity", 3) it acted in defence of abstract painting and its value, its self-referential nature and art-as-art, 4) and therefore each form of art ought to narrow its area of competence, thus securing the accomplishment of abstract expressionism which he also dubbed "American-style painting"[3] One could further see Greenberg's project as a materialistic attitude as it eschews religious and metaphysical propositions; the paintings are an assertion of fact, of its own physicality and bodily sensibility towards an aesthetic experience. Such art is thus "exclusive of intellectual, effective, spiritual, moral or social relevance" (Tekiner 2006: 35). In this way one might call Greenberg a radical aesthete, though different to Bell in that he found modern art to be the truest indication and reflection of his version of formalism, whereas Bell may have found it in so-called primitive art (though not necessarily so).

If art according to the formalist theories enumerated above set "high art" apart from other objects, then in the following critique, quite paradoxically, it is precisely in arguing for "formal harmony" and the like, that points the way to a recognition and consciousness that the "common object" indeed can be considered in formal, aesthetic terms as well. This then argues against art's separateness or at least diffusion into other domains. Furthermore, where art itself denied the formal as in Duchamp's intention regarding his ready-made's, and in Conceptual art, this in fact simply demonstrated that art itself need not only be about formal beauty, and thus if art itself could be redefined, then so too its assumed monopoly as to what constitutes aesthetic, formal beauty. Moreover, formalism transmutes precisely into and as a "play" of surfaces. Nevertheless, I would contend that no one theory is all-encompassing, so formalism itself is limited in its explanatory scope.

My arguments against formalism are related to an extreme version of the theory. Zangwill (1999) proposes what he terms "moderate aesthetic formalism". Here some aesthetic properties of a work are formal, while others are not. He incorporates a Kantian system of thinking when he argues that a work of art contains non-formal aesthetic properties or in Kantian jargon "dependent beauty", namely concept, end, purpose, fulfilling an intention, or function and formal properties or "free beauty", where there is no end purpose, such as, drawing from Kant, wall paper designs, music without words. A combination of free and dependent beauty means that one can say that "there is beauty in the way something is represented, which is beauty over and above its beauty as abstract design. Something is not just a beautiful pattern and a picture of a tree, but beautiful as a picture of a tree. The two properties are not merely added but multiplied" (Zangwill 1999:615). It would be too extreme as in Bell's formulation to say that all aesthetic properties of representational paintings are formal. Bell plays down the representational element. In Zangwill's more moderate form, the abstract, the formal and the representational all find a place simultaneously. In this version art's aesthetic "purity" is compromised, but at the same time lends itself to the invocation of "other" aspects of life. In this sense, formal, aesthetic 
"play" creates a "body" that is both logically self-referential and has content, the "truth" of which cannot be ascertained. In this respect, even where we are enjoined to see one aspect, namely the aesthetic, the extra-aesthetic is still latent. The beautiful and the symbolic in art are interrelated and ought not to be taken as final in and of itself. One implication is that art does not assume the monopoly on what counts as beautiful, for example, and yet one can extend art's concern with beauty to other areas of life. This immediately also means that such "other" areas also have symbolic value. In this way, an analysis of art can be applied to readings of such other domains, such as sport.

\section{Application and Methodology}

\subsection{Towards a Formalist Definition of Sport}

One may ask in what way formalism applies to sport. One obvious point of convergence is that sport, to a greater or lesser degree (depending on the sport), includes aesthetic components (formal harmony) whether as participant or viewer. It seems clear to me that we should experience or describe a cricket stroke, for example, as formally attractive, that is, that it exemplifies grace, poise or delicacy. Or that a certain manoeuvre in a team sport such as soccer dazzles and weaves a wondrous pattern before one's eyes (or as experienced as such through "playing") and commentators go so far as to declare that a certain goal was simply sublime, that it was aesthetically pleasing.

Although at the outset I should state that it is not my intention to argue that sport is art, the question does come into view when we consider sport as aesthetic. Arnold (1990) argues that to say that sport is aesthetic does not mean it is art, for the aesthetic is a broader category than art, even as art is the paradigm case of the aesthetic. To argue that sport is art, because it is aesthetic, conflates the concept of the aesthetics with art, as hitherto mentioned. But something need not be considered art in order to demonstrate that it can be beautiful or a source of aesthetic experience. Sports, it will be argued, exist on a continuum: one pole are those sports where the aesthetic is not important, another, that aesthetics is integral to the very nature of the game and, indeed, some sport may be considered art, assuming one were to accept a definition of art along traditional lines, that is, the fine arts. In drawing out such parallels, perhaps we come that much closer to defining art or sport, though significantly as a function of each other, thus denying a severance between the bodily activity of sport and the so-called more refined arts.

Although sport can be described, interpreted and evaluated it does not and cannot be a necessary guarantee for providing an aesthetic experience. Conversely, an aesthetic object need not be art, but it obviously could be. Best (1978) distinguishes between non-aesthetic sports or purposive sports and aesthetic sports. The former are those sports that can be specified independently of the manner of achieving it as long as it conforms to the rules (for example: football, rugby, hockey, track and field, baseball, tennis and so on). In such sports, the aesthetic is not intrinsic. It is simply the most points, goals or best times that are essential. They can be aesthetic, but these moments are not necessarily or logically a part of their purpose - their purpose can be fulfilled without reference to the aesthetic. Then there are the partially aesthetic sports whereby: "...the aim of the sport cannot intelligibly be specified independently of the means of achieving it" (Best 1974:28). Arnold cites gymnastics, synchronized swimming, ski jumping and surfing as examples because the way or manner of performance is important, a necessary feature of the activity. Importance is given to "elegance", "ease", "precision", "style" and "rhythm", "faultless execution", "right amount of force"..."originality...virtuoso integration of parts" (Arnold 1990:162/3/4). The movements may be matched to music and a formalist description might be most applicable. Thus: "The aesthetic sport in one in which the purpose cannot be specified without reference to the aesthetic manner of achieving it" (Arnold 1990:167). Then there are those sports that are not just aesthetic, but may be considered art, for example dance and mime, wherein there is no separation between the nature of the activity and its mode of presentation. One might call it an embodied meaning, as Friessen (Arnold 1990:167) states: "the dancer must remain one with the dance to preserve the unity and continuity of the aesthetic image. The technical competence of the dancer includes not only the physical skills required to perform the dance, but the ability to exist within the dynamic illusion of the dance." The difference between being simply an aesthetic sport and being an artistic one, is that in the case of the former the gap between the purpose and the aesthetic is never entirely closed; the purpose could still be achieved in absence of the aesthetic/formal coherence.

To give substance to the idea that sport is certainly aesthetic as it is concerned with formal coherence, we can look at the writing of Smith (2006) who argues that "significant form" (borrowed from Bell) - the relationship of structured, meaningful cultural activities in a given time and place and the mastery of these forms by a few, as well as the active (interpretive) role of the media in the event - is the crucial element in the game, rather than just success or winning. Smith (2006:47) said the following about Wooley, the cricketer: “...he gave thousands and thousands of his countrymen a conception of the beautiful which artists struggle to capture in paint and on canvas...and they recognized in him something beyond the average scorer of runs, some elegance of line and harmony of movement which went beyond the figures on the scoreboard. That, indeed, will give him his place in the game, a place higher than many who won more matches for their side". Smith (2006) treats cricket with the kind of interpretive parameters usually reserved for "higher" 
forms of culture; that it too should inspire a sonnet. He wrote that "the style of play, the attitude of the players, the discovery of new shots or styles of bowling ... these are the significant formal aspects of the game in the same way that modernism or tragic realism are formal literary developments which can be historically discussed". Hence, we find a list of sports writers in Smith's mould as they describe signature strokes, posture, response to specific circumstances and the like. One may thus argue that there is a formal element to sport, both in terms of historical formal developments within the game and individual style.

Lowe (1977) also relates sports-movement and aesthetics. He speaks almost mystically of the "total comprehensive capacity" (1977:45) and "imagery" (or the sports moment). As I understand it, he refers to the ease and effortlessness of correct play as well as the poignant instance of a good performance, the result of which is a picture of high definition [4]. Furthermore, this "high definition" may be described as beautiful, pleasurable and joyful for participant and viewer alike. The price for beauty is effort. Another way of describing how this beauty is achieved is to say that sport is a "relational pattern" (Smith 2006). Smith perhaps takes his cue from Bell as this "relational pattern" consists of pure forms and unity and is thus comparable to what Bell appeals to when he talks of significant form.

The beauty of movement and its formal ordering, if you like, is a result of the fine-tuning of the mind acting through the body. Suffice it to say at this juncture that the very competence of the athlete is as a result of the training of the (mind and) body in a formal language, both beautiful and effective as it pertains in specific and distinct ways, depending on the sport. Weiss (1969:68) helps clarify the type of formal harmony of the body that I am arguing for in the following quote:
...he who makes golf his game finds that he never comes to the end of the work of perfecting his stroke. His is the perpetual problem of getting his wrists, fingers, arms, legs, shoulders, neck, head and hips to function in harmony. The mind makes the body be almost indistinguishable from himself. He must submerge himself in it, at the same time that he keeps it under his control. Only because he has become his body for a while is he able to bring about the results he seeks.

In this quote, one sees that one can only achieve and enjoy a specific sport if one makes out of one's body a form that articulates a sense of constructive action and unity of parts; achieving this may be beautiful and invite aesthetic contemplation and the like.

Weiss continues and makes the point that an athlete actually arrives at this point where he hardly notices his equipment. $\mathrm{He}$ acts with and through it, as though it were just his body extended beyond the point at which it normally is, or can function. The hunter hardly knows where his arm and fingers end and his rifle begins. It is barely a metaphor to say that a polo player is a centaur (adapted from Weiss 1969). The athlete, as an exemplar of human perfection in the art of running, jumping, wrestling and so on offers the viewer and the less serious or talented sportsperson, no less than the athlete himself or herself, a vision of beauty and grace, of the body-beautiful as the athlete's coordination, responsiveness, attention, efficiency, devotion and accomplishments, his or her splendid unity with the equipment are all geared to produce a result at the limits of bodily possibility which set the athlete apart from the rest of men. When we watch sublime play or somehow perfect a movement, it is the form that we are admiring or that we have created and developed. I think Weiss sums this up best in the following line: "Something similar to what the mathematician attains when he thinks (and/or does mathematics), the athlete attains when he acts..." (Weiss 1969:247). It is precisely the mastering of language (of symbolic logic or precise movements) that engenders a formalist conception of say, sport, which is articulated in a mind acting in a well-structured manner through the vehicle that is the body and the equipment of a particular sport.

\subsection{Gumbrecht's Notion that Sport is Aesthetic}

I have been arguing that insofar as sport may be concerned with an aesthetic concern, there is a formal dimension that can be construed into a formalist theoretical model in order to develop a theoretical parallel between art and sport, if not convergence. Gumbrecht lends further weight to this thesis and in what follows I shall describe his ideas on the matter.

The shared aesthetic trait in art and sport is what Gumbrecht (2006) presents to the reader. Gumbrecht (2006), a leading figure in the philosophy of aesthetics offers in his book, In praise of athletic beauty (2006) a new aesthetics of sport in order to retrieve sport from the margins of intellectual enquiry within the "global academia". He begins by challenging the tendency within the western academy to deny athleticism intellectual praise (the Classical Greeks were an exception). This has occurred because human physicality and related sportive activity has often been pushed to the margins of western cultural life, where it joins others forms of popular culture outside the realm of "high culture". This situation can only be redressed when sport performance is reclaimed as potentially beautiful (or at least, artistic), and by extension, establishing a case for an aesthetic essence in sport which is tantamount to a formalist project in that an aesthetic dimension can be reduced to - or analysed as - a set of formal properties or an abstract configuration of sorts. 
He does this by looking at Kant's notion of disinterest, those moments of aesthetic transcendence resulting in the observer or listener moving into a state of pure appreciation, detached from other dimensions of worldly existence. It is this that creates the beauty of art. Gumbrecht uses the term "focused intensity" - borrowed from the swimmer Pablo Morales (2006:49) - to describe the disconnectedness both athletes and spectators experience at heightened moments of sport appreciation. The wondrous surprise occurring in the moment of appreciation "can be thought of as a kind of epiphany" (Gumbrecht 2006:54). Therefore, the aesthetics of sport recalls a kind of artistic inspiration.

Beauty in sport arises from the Greek concept of arête (striving for excellence) and becomes apparent to the appreciative eye. This arête necessitates agon (competition). Characteristic of this beauty is a certain effortlessness and flow - "the beautiful athletic movement, resulting in a moment of transfiguration for its appreciator, comes from deep within the athlete and is projected outward" (Gumbrecht 2006:70).

In the section titled "fascination", by which Gumbrecht means the dimensions of interest that compel people to watch sport, an expectation and anticipation of sporting excellence is created (Gumbrecht 2006). The dimensions of spectator fascination that Gumbrecht discusses include "suffering", "grace" and "timing". Individual suffering in athletic performance is the result of the confrontation of the potential of death. He uses the example of Dempsey, the heavyweight boxer, to illustrate that it was in bruising defeat and suffering that he triumphed, that afforded him public reverence as a champion. The spiritual side expressed in defining "grace" is defined by the image of the great athletes as they appear to move "not from the instructions of the brain but by command from some higher force [3]" (Gumbrecht 2006:169). Gumbrecht hails today's sprinters and swimmers, linebackers and forwards, as icons of muscular grace. And timing "good timing ... refers to the case of perfect fusion, between a perception of space and the initiation of movement" (Gumbrecht 2006:198). The interconnectedness of time and space occurs in a way familiar to the arts and is the meeting point of arête and agon. Violence is intrinsic to the competition for space; here one may say that beautiful moments arise, and timing is about avoiding or producing violence. Thus, Gumbrecht is finding a cognitive voice for the praising of the athlete, a veneration associated mainly with the artist.

In the final section he makes a case for "gratitude" (Gumbrecht 2006) being given to the athlete for his or her creation of beauty, via the terms "watching" and "waste". He writes about two aspects of watching sport, namely analysis and communion. Analysis is a more personalized viewing experience whereby sport is watched on television with a critical eye. The communal watching experience [5] - that Gumbrecht (2006) prefers - occurs at the sport stadium. Here followers are collectively gathered usually in support of a team. Gumbrecht believes that there are moments when the energy of the crowd connects with that of the team and suggests that in this ultimate moment of communion the prospect of collective aesthetic experience is heightened (Gumbrecht 2006). "Waste" refers to athletes whose lives fell away since their retirement from sport, but this would not indicate that they wasted their time; their subsequent demise is not indicative of waste, but sacrifice. Thus, those of us who have seen beauty in the performance of the sportsperson must be grateful because the potential sacrifice gives to us an awareness and appreciation of joy in our own mortal existence. So Gumbrecht appears to make the case that sport certainly is aesthetic. That the "wow" [6] we may feel for a painting correlates as "aesthetic entities" to that of the "wow" we feel for sport. Therefore, an analysis or understanding of sport requires a formalist theoretical perspective as, in the making/constructing of beauty, sport is composed of a language of sensory artistry.

Applying Gumbrecht's “findings”, Regier (2008:31) analyses Zidane's winning goal for Real Madrid in the 2002 Champions League final as beautiful. Such a judgment satisfies the following criteria:

1) The goal can be said to be "purposive without purpose" because it is a goal as of its kind with no further function.

2) It represents disinterested beauty - regardless of whom one is supporting one can appreciate the goal.

3) One ought to claim subjective validity universally, no necessary prior cognitive stock is required, that is, contextual knowledge. Though one cannot prove its beauty, the Kantian model is maintained.

Following Gumbrecht, Regier maintains that sport tends to the condition of beauty. In appealing to beauty, one is lead to a formalist-type description of the performance or viewing thereof. This may explain the attraction of sport on both a conscious and sub-conscious level. In other words: while sport seems to be the counteraction if you like to contemplation, Gumbrecht now contemplates it (sport) which in a sense breaks the circle (of the polarity of "action" and "contemplation").

\subsection{Critique of Formalist Theories of Sport}

The limit of the formalist project as it applies to sport is that (some) sport is obviously not "disinterested" - there is always some objective within the game itself, namely to win, rather than simply movement for its own sake. Such activities have a competitive and economic reality and are wedded to institutional, social and political concerns. 
Moreover, perhaps one is going too far to claim an aesthetic experience is induced by sport. Given its competitive nature, perhaps it is a minor point to claim an aesthetic dimension. The ubiquitous nature of sport means precisely that it is amenable to all strata of society, that is, it is easy to enjoy as both viewer and practitioner precisely because it does not require a special aesthetic sensibility, an intellectual response or an ability to be sensitive enough to intuit a formal structure within a particular play or the like. It is part of mass culture and in this sense, rightly or wrongly, perhaps departs from the fine arts. This remains an irony as often the very aim of the artist is to appeal to everyone.

A further critique is taken up by Edgar (2013). Edgar (2013) writes that the aesthetics of sport is a largely unchallenged presupposition of much aesthetics about sport (Lowe 1977, Gumbrecht 2006, Moller 2003) and a theme in de Courbertin's conception of Olympism (2000, 605-634). There is an assumed centrality of beauty in aesthetics generally and in particular in its application to sport. But the aesthetics of beauty in sport is ambiguous and vague. It's a hangover of eighteenth century aesthetics that affirms the illusion of "giveness" and modernist self-critique that disrupts the "given". In agreement with Edgar (2013) this leads to "disenfranchisement" of sport (and art for that matter), that is as seeing it only fit for sensory pleasure and the like and an appeal to a vague intuition of beauty. This is so as to argue that sport has intrinsic aesthetic properties, is to see it as lacking relevance to everyday life. It is reduced to a kind of sports-for-sports-sake mantra, which like art-for-art's sake, is problematic. One may take this idea of "disenfranchisement" further by noting that the divorce of experience and the aesthetic object from any non-aesthetic concerns (historical, political, psychological), for example in Gumbrecht on sport or Bell on art, is simply to look at syntax, not semantics. It is to see sport as a kind of Sabbath from everyday life that expresses nothing. As Best (1974, 1979) makes the strong point that sport (unlike) art has no content or rather does not comment on life as such. Sport becomes an embodied presence obdurate to any intellectual interpretation in this respect. Aesthetic judgements of beauty, according to Edgar (2013:103) only expresses a personal and idiosyncratic satisfaction, then it is not available for discussion and cannot be contested discursively and intersubjectively.

Arnold (1990), furthermore, points to the fact that it need not be the "beauty" in sport that so appeals, but the illustration of skill, and talent. In that sense, what we admire in a good documentary photograph capturing the sporting moment need not be dissected in terms of its formal components and arrangement, but simply the ability to perform at a high level. We marvel at the ability to perform a certain manoeuvre, rather than the creative capacity to express something meaningful through formal relationships. It is therefore not meaning and beauty that we see in sport, but craft. Personally, I do not endorse this view, but rather subscribe to the view that sport can be aesthetic and meaningful and to that end, formalism as a theory may certainly be a useful tool in our understanding sport.

\section{Result}

\subsection{A Deduction: The will to Form}

Having made the last point, I wish to propose a deduction that devolves from such a position and coheres at the same time with a formalist approach to art. Fundamentally, if one subscribes to the view that art and sport appeal owing to their formal structure and thus, their beauty, then could one not claim that inherent in the desire to make art or to move in specific ways, is what I term "a will to form"? Secondly, but no less important, is a kind of freezing of time, a capturing of the moment or the creation of an eternal present (this applies to documentary photography of sport and the like), the latter being a sub-category of the former. It is to these deductions that I now turn.

I refer the reader to Brancusi's "Bird in Space" [8] (1928) and an imagined documentary photograph [9] of Yamashita's judo throw. What could these two images have in common? There is a certain tension, weight, physical aliveness, a sense of grandness, even transcendence in both images. I attribute such perceptions to the fact that such imagery appears to me to exemplify formal mastery.

Brancusi makes the viewer feel a sense of upward joyous surge, a sensitive linear mobility that is all the more sacred given the gold bronze colour. His sculpture is soft and sharp simultaneously, strongly vertical and yet curved and organic. Brancusi was quoted as saying: "art must penetrate into the spirit of nature and, like nature, create beings whose forms and lives are independent" (in Walther [ed.] 2005:427). In this quote, the artist reveals the desire to create new, original forms, to create forms that exist independently, that speak the silent language of art. Form is thus the vessel of meaning and formalism, a theory that emphasizes the unique visual language in contradistinction to other forms of art or languages and the aesthetic disposition that certain artworks may induce in the viewer, helps clarify why we may attend so favourably to a work such as this.

In its abstract quality or its abstraction, Brancusi desires to reveal the "inner", "essential" reality. Now, although the position has being criticized (of an "essential" reality), this modernism certainly holds a kernel of truth and "he (Brancusi) unerringly and painstakingly seeks an increasingly pure and perfect body of form that is transcendental in its immaculate finish" (in Walther [ed.] 2005:425, brackets my inclusion). Formalism therefore may be "spiritual" as it speaks of the "essential form" containing "metaphysical reality" (a la Bell) or as is the case with Greenberg, 
materialistic, in that we simply assert the fact of a form without attending to meanings. In either case, it appears that there is an inner need for form, a desire to be graceful, harmonious, rhythmic, effortless, in control, to flow, to hold power and if one cannot be these things or some of them, to realize them through visual perception of form, in an artwork!

We may then describe dance and performance arts as poetry in motion, as a revelation of symmetry, unity, as not been discordant. We may perceive qualities of balance and timing, pattern and design ... all this through creating form or simply viewing eloquent forms such as in Brancusi's sculpture.

In a self-same manner, the imagined documentary photograph, for example as recorded in Kodokan Judo (1986:59) inspires a sense of balance and power. The two fighters create a vertical line offset by the strong horizontals of the background. The sense that the physics of stasis is about to change as the O soto-gari throw [10] will inevitably lead to the demise of the one fighter - that moment before chaos, is captured and we momentarily witness the intense, forceful action just before the plunge. Through this image, we can learn what is required to execute a good throw (or photograph) and choose to identify with Yamashita. In so doing, we project ourselves into the form, as one may do so with Brancusi's sculpture, and in this alignment of self with image, we transform ourselves, we intuit that the form poses a question. Perhaps the question is not only as a result of its aesthetic quality; perhaps it enters the domain of our will do we wish to feel like a "bird in space", can we also perform a judo throw with such gusto and verve or fall victim to it? My contention is that images enter the mind on this level, because we need to see who and what we are or can be in order to think on it: it is the will to form that makes us.

Or in other words, we may say of art that it allows us to see the world from another perspective, as with Hegel's notion that art is the midway between sensual embodiment (form) and the abstractness of pure thought (idea). That which makes meaning is sensibly exemplified, rather than understood in logical terms alone. Sport too may also reveal an action (form) encoded with a picture of the sublime (idea). Brancusi's "Bird" is finite but its eloquent form hints at the infinite or that which is of the mind, the realm of ideas. The sporting documentary photograph captures the singular moment of a series of movements that was the alive, vigorous activity of that sporting event, and in that stillness creates the potential for that which has no limit - the idea of the sublime or the realm of ideas.

When we see an image or picture (a painting, a sculpture, a documentary photograph ...), the flow of time is arrested. When we watch a sports event, the world of make-believe [11] usurps the rather more serious flow of time that is life. In this way, art and sport transport us to a kind of eternal present. Halt (2008), reflecting on Gumbrecht, believes that in the evocation of athletic beauty, the "everyfan" as he calls it, suggests a choreography of beautiful play in which "... the sudden, surprising convergence of serial athletic bodies in time and space" (Gumbrecht in Halt 2008:52) create a larger than life moment. In the athletic ideal there is an aesthetic quality. This is also due to the kind of sculptured body of the athlete (demagogue). The sports arena is an ideal space (time) in which the moment is elevated. Halt argues that there is a sense of "oneness" in such "moments of intensity", a feeling of communion, even a "momentary loss of self" or transcendence of individuality that actually begins with beauty. He continues by saying that "the unexpected appearance of a body in space, taking a beautiful form that just as quickly dissolves, can be thought of as a kind of epiphany" (Halt 2008:56). I would claim the same effect may be inspired through the images presented in this section.

Gumbrecht (2006) makes the point that "Beauty is not the goal of competitive sports, but high level beauty, the human beauty we're talking about here is beauty of a particular type. It might be called kinetic beauty. Its power and appeal are universal. It has nothing to do with sex or cultural norms. What it seems to have to do with, really, is human beings reconciliation with the fact of having a body" (Gumbrecht in Young 2008:10). It is the pre-discursive body through which the self acts (runs, paints ...); it is the body that becomes the very materials (the whole body, just the hand ...) out of which form is composed. And in that presence of self through the body, there can be a dramatic moment, a sensual, though aesthetic, perception. One is not referring elsewhere or treating the sports moment or the execution of an artwork, as symbolic. That is, like Kant's ideas, we attend to beauty for its own sake, without a definite concept, via the free play of imagination and understanding. It is disconnected from everyday life, and not grounded in concepts, since nothing in the everyday world is at stake (it's really a game, fantasy, a picture as developed in the previous chapter under "imagination") though here it serves to elucidate the question of form in and of itself.

\section{Discussion}

What I have being pointing to is the role of the pre-discursive body [12] in human meaning and understanding (c.f. Potgieter 2009), the inscribing of the body in order to be aesthetically moved by the sensory impressions that constitute art and sport.

Now such embodiment in sport is made possible by the formal set or code of rules that make a particular sport possible and that conspire, as it were, to create coordinated play. Bernard Suit's "The Grasshopper: Games, Life and Utopia" puts forward various notions of games, play and Utopia in a witty and entertaining, if not seriously philosophical 
account.

One of the major aspects of Suit's argument is that one can define, for example, "games". Here he parts way in quite emphatic form from Wittgenstein who argues that games and many words in general cannot be reduced or easily defined, that at best there are simply "family resemblances". In the form of Ancient Greek dialogue and with the use of examples, some rather funny, Suit's defines games as fulfilling three main criteria: 1) the prelusory goal, 2) the lusory goal and 3) the lusory attitude. The first has to do with a goal that is independent of the game, such as in golf that a ball enters the hole; the second has to do with a goal internal to the game, such as in golf breaking par and the third definition is that players accept the rules of the game, which are not the most efficient means of accomplishing the task or goal and that make the game possible. He further argues that games are autotelic, meaning that they are good in themselves and not necessarily instrumental.

So, we are left with a quandary: We may be able to define games and the playing of games. We may describe them as "sabbath" from ordinary life, a refuge of sorts and an ideal way of being and doing. We may further argue that to the extent that we play - that is, we conform to agreed rules, so we have fun and forget the seriousness of life - and thus we have entered a portal to a better world. However, it is not a simple as that. In fact, this may be incorrect.

For games - and here I incorporate games of make-believe, the arts, intellectual pursuits, board games and sports, perhaps even every aspect of everyday, mundane life as a philosophy in sync with the field of everyday aesthetics - are not that innocent and playful. That is, the games we play to put it bluntly reflect, reinforce, divert attention (one might call it entertainment or leisure), ideologically brainwash and appear to unify when in fact that mirror or even extend real-world strive. This is evident in sport for example which is often used for political and/or economic ends. The example of Hitler's Berlin games of 1936 is the most glaringly obvious, but one can find this in subtler ways where sport galvanises only to separate and divide and erect nationalistic boundaries. Art, another institutional game (obviously different to say sports-games in that the rules are less iron-clad, though there are basic rules to as it were play the game we call art) has historically being a powerful marker of the political, philosophical and ideological agendas of certain groups.

However, it is not all doom and gloom, suffused with manipulation, deception, aesthetic trends and even war. There is a strong "play element" (read: will to form) in culture that is perhaps free from systems of control. In this respect, games such as art and sport are ways of connecting people and finding joy, triumph and success through the medium that is that game. Sport, for example has the power to bring people together, even when political and economic solutions are not at hand. Art can often ignite and uplift consciousness, potentially even giving a vision of new ways to see old situations, and to revel in aesthetic delight to increase sensitivity, compassion and empathy. And formal rules assist in realising such a vision.

So, if games are a two-edged sword and if Utopia is a paradox in that its accomplishment defeats the purpose (what meaningful can we do in such a Utopia?), then how can play and struggle, work and fun contribute to a better world? Suit's version of Utopia falls short in that it presupposes, as I understand it, that there is a final resting place where everything is abundant, where our knowledge is complete. Such a picture is far-fetched.

Perhaps a better version of his idealism and the very reason behind the so-called posited will to form, is to maintain the importance of play and games and that it forms part of culture broadly defined, but that there is no ultimate utopia. For our games as I have argued are already enmeshed in ideological and often immoral pursuits. Secondly, and this is perhaps the more important point: there is something about life which is real and cannot be captured by the idea of a game. Because games are a kind of reverie, an imaginative construction with arbitrary rules, its play-element masks the reality and sacredness of life itself. Put in other terms we might say that love is not simply a pursuit that ends in victory or loss, but that it is a real quality that cannot be quantified and measured, that cannot be expressed in a game or framework of any kind. Friendship then is meaningful precisely because of its humane quality as is universal brotherhood, but as Suit's warns this is not to be found first by playing at something, but in fighting for core principles. To fight in the boxing ring is not to fight in life proper. And while it may be noble to contest and improve one's game, this may have little to do with actual Utopia, or rather with life itself. Paradoxically though, it appears that such ideals are in fact found within formally determined games that are rule-bound.

Another way in which one might argue for the will to form is in the imaginative image of the embrace of art and sport, what I have termed the "intertwining argument" whereby there is a co-existence of art talk, sport talk and aesthetic meanings. An example of this conception can be seen in the writings of Kupfer (2001:19) who writes (on sport):

...perfection in negation lies at one pole of aesthetic experience and human life - the pole of austerity. It is minimal, clean and simple with counterparts in sport, in both nature and art. In nature, we delight in the austerity of stark vistas of desert or ocean. The perceptually boundless expanse of sand or water provides an aesthetic intensity that is captivating in its bare 
repetition. In art, we appreciate the clean lines of Brancusi's 'Bird in flight' or the minimalist painting of Rothko. At the other pole of experience is plenitude and proliferation. We also enjoy the seemingly endless profusion of flowers in a meadow or the starry galaxy that appears to spill forever into inky space. So, too, in sports. The counterpoint to perfection as negation is the aesthetic exuberance of abundance: the quarterback who throws for over 400 yards or completes a handful of touchdown passes; soccer and hockey players who score three, four, even five goals in a game...

We can enjoy abundance and proliferation as well as negation and austerity in nature, art and sport. The aesthetics of abundance and negation are "intertwined" in sport as art-like.

If we can thus metaphorically fuse art, sport and the aesthetic, then it seems that they can fulfil similar goals, that their task is somewhat akin. In fact, as Elcombe (2012:71) asserts: “... due to sport's span of passionate appeal - from the local to the global - as well as its irreducibly embodied, kinaesthetic nature, sport is well positioned to perform art's cultural task better than traditional forms of art". Here art and sport are "intertwined" not in the sense that sport is simply dubbed "low" art, but in that sport as an aesthetic, cultural phenomenon may continue the work of art, namely as a meaningful human practice with the intent that as Alexander (1993:205-6) puts it - "a sensed texture of order, possibility, meaning and anticipation" - is potentially experienced or willed or formed. In other words, this "texture" of meaning is presented in sport as it is with art, a "texture" that one can grasp experientially and aesthetically that gives rise to pleasure which, at the same time, gives one a sense of conceptual meaning should we choose to perceive it so.

\section{Conclusion}

I would further conjecture that this "will to form" is predicated on the need humans have for order, pattern and harmony [13], sensory stimulus that calms or exhilarates us. In that sense, art and sport might offer us a vision of clarity and precision. Form is therefore necessary for intellectual, sensuous, intuitive and emotive dimensions of being, the four-pronged compass of human agency as expounded by Jung (1875-1961). Thus, a theory of formalism applies equally to art and sport. A moderate formalism as proposed by Zangwell that includes content and form may best articulate the aesthetics and extra-aesthetic dimensions that inheres in both disciplines or better, through which one may gesture towards an inter and trans disciplinary exploration. The added value that this paper then suggests is to 1) regard the aesthetic as pervasive and 2) that an everyday aesthetic overlaps with art theory and practice. The limitations of such a theory is the lack of definitive boundaries and categories, so that it is difficult to define one's terms right from the start of analysis. Future research may even consider the benefits of art on sportspersons as a kind of therapy which may impact positively on sports performance.

\section{Notes}

1. Kant appears to be saying this as if the beautiful object is aesthetically pleasing, that is, if its spatial and temporal properties (proportion, line, shape) are aesthetically pleasing, then it reveals a "purpose without purpose" - it is as if it were designed for us. Or in other words, one can claim universal accent; taste is not purely subjective and arbitrary.

2. Hansliek's (1986) musical formalism is such that beauty is specifically musical, that is, no extra musical (aesthetic) concerns are required. Circumstances and external background of the composer are not important, only the structured pattern of sound is relevant. He thus argues for free or formal beauty as opposed to non-absolute music which depends on a non-musical purpose such as marching, dancing, narrative, meditating, praying.

3. This is a curious label as it contradicts an outright a-historical, formal approach and becomes a form of nationalistic propaganda.

4. Which is further related to dance and by extension, music.

5. One may call this "higher force" the subconscious or "great reason" (following Nietzsche). One may note then that the sportsperson and artist need access to a level beyond the conscious level.

6. I cannot help but feel a sense of communal kingship is established at the theatre as if the audience goes through the drama together. To a lesser extent, the fine arts gallery offers a space of communion, certainly where performance art is concerned, though here, in general perhaps the experience of the gallery is rather more isolated.

7. This "wow" may take a number of forms depending on the language-game, or "form of life", each incommensurate and none ultimate..

8. Bird in space, 1928. Polished bronze, height: $137.2 \mathrm{~cm}$. Circumference: $9.5-37.7 \mathrm{~cm}$. New York. The museum of modern art. In Art of the $20^{\text {th }}$ century, vol. ii, Tachen, Walther (ed.), photography: K. Hannef,

p 427. 
9. In Kodokan judo, J. Kano, Kodansha international, 1986, photography: Kodokan judo, p 59.

10. Judo is my area of expertise, being a $2^{\text {nd }}$ dan and sensei (teacher) so I have a particular passion for the form exhibited in the sport/art, especially the Kata which really means "forms" and "randori" which is creative, free practice.

11. Depictions of early cricket matches, for example, are almost as potent as hunting prints in constructing a pastoral idyll in the midst of the Industrial Revolution. Or in tennis we have young men and woman in white set against the soft grass of summer. Other than spatial considerations, there are technical aspects as in the notion of "classic" shots, and an aesthetic orthodoxy, where cricketers, for example tended to be captured in portraits with one hand on the hip and the other on the handle of the bat in a heroic manner.

12. The pre-discursive body refers to imagination, feelings/emotions and the "body", that is to say, physical embodiment, wherein are included such properties as "weight, balance, containment, in-out, front-back, texture, line, colour, force, gravity" (c.f. Restoring the body in Western philosophy and art practice, Potgieter, F, Unisa, 2009) which conspire together under suitable aesthetic conditions.

13.C.f. The mind, Wilson, R, Life science library, 1971. Psychologists have conducted a series of experiments proving that the lack of sensory stimulus or stimulus that is chaotic and the like, is dangerous to human health. We have some kind of drive to see and hear a sequence that produces a coherent state of mind, that is, forms that "speak to us", a pattern.

\section{References}

Arnheim, R. (1974). Art and visual perception: a psychology of the creative eye. Los Angeles: Berkeley University Press.

Arnold, P. J. (1990). Sport, the aesthetic and art: further thoughts. British Journal of Educational Studies, xxxvii(2), 160-179. https://doi.org/10.1080/00071005.1990.9973844

Bell, C. (1958) [1913]. Art. New York: Capricorn.

Best, D. (1974). Expression in movement and the arts. London: Lepus.

Best, D. (1978). Philosophy and human movement. London: Allen \& Unwin.

Best, D. (1979). Art and sport. Journal of Aesthetic Education, 14(2), 69-80. https://doi.org/10.2307/3332478

Best, D. (1986). Sport is not art: professor Wertz's aunt Sally. Journal of Aesthetic Education, $20(2), 95-98$. https://doi.org/10.2307/3332697

Bywater, W. G. (1975). Clive Bell's eye. Detroit: Wape State University Press.

Crawford, G. (2004). Consuming sport: fans, space and culture. London: Routledge. https://doi.org/10.4324/9780203493922

Dowling, C. (2010). The aesthetics of daily life. British Journal of Aesthetics, 50(3), $226-242$. https://doi.org/10.1093/aesthj/ayq021

Edgar, A. (2013). Sport and Art: An essay in the hermeneutics of Sport. UK: Routledge.

Fabozzi, P. (2002). Artists, critics, contexts: readings on and around American art since 1945. New York: Prentice-Hall.

Gombrich, E. (1960). The story of art. London: Phaidon.

Gombrich, E. (1962). Art and illusion: a study in the psychology of pictorial representation. 5th edition. London: Phaidon

Greenberg, C. (1961). Art and culture: critical essays. Boston: Beacon.

Greenberg, C. (1971). Necessity of formalism. New Library History, 3(1), 171-175. https://doi.org/10.2307/468386

Greenberg, C. (1973). Art and culture. London: Thames \& Hudson.

Gumbrecht, H. U. (2004). Production of presence: what meaning cannot convey. Standford:

Gumbrecht, H. U. (2006). In praise of athletic beauty. London: Cambridge University Press.

Gumbrecht, H. U. (2006). In praise of athletic beauty. Sport, Education and Society, 13(2), 239-246.

Guyer, P. (1997). Kant and the claim of taste. Cambridge: Cambridge University Press.

Guyer, P. (2011). Kant and the philosophy of architecture. The American Society for Aesthetics, 34(2), 7-19. https://doi.org/10.1111/j.1540-6245.2010.01442.x

Halt, R. (2008). The appeal of spectator sport. Sport in History, 28(1), 51-63. https://doi.org/10.1080/17460260801889228

Harrison, C., \& Wood, P (eds). (1993). Art in theory: 1900-1990 - An anthology of changing ideas. Oxford and Cambridge: Blackwell. 
James, J. L. R. (1963). Beyond a Boundary. Trinidad/UK: Hutchinson.

Kant, I. (1952). [1790]. The critique of judgment. Translated with analytical indexes by Meredith, J. New York: Clarendon.

Kupfer, J. (1983). Experience as art: aesthetics in everyday life. Albany: State University of New York Press.

Kupfer, J. (1997). Swift things are beautiful: contrast in the natural aesthetic. Journal of Aesthetic Education, 31(3), 1-14. https://doi.org/10.2307/3333483

Kupfer, J. (2001). Perfection as negation in the aesthetics of sport. Journal of the Philosophy of Sport, XXVIII, 16-31. https://doi.org/10.1080/00948705.2001.9714598

McLaughlin, T. M. (1977). Clive Bell: aesthetic tradition and significant form. The Journal of aesthetics and art criticism, 35(4), 433-443. https://doi.org/10.2307/430609

Potgieter, F. J. (2009). Restoring the body in western philosophy and art practice. Pretoria.

Regier, A. (2008). Judgment and experience in the language of confessional sports. Sport in History, 28(1), 26-38. https://doi.org/10.1080/17460260801889194

Sheppard, (1987). Aesthetics: an introduction to the philosophy of art. Oxford: Oxford University Press.

Shusterman, R. (1997). The end of aesthetic experience. The Journal of Aesthetics and Art Criticism, 55(1), 29-41. https://doi.org/10.2307/431602

Smith, A. (2006). The conception of the beautiful: C.R. James Glasgow's cricket articles, 1937-38. The International Journal of the History of Sport, 23(1), 46-66. https://doi.org/10.1080/09523360500386435

Suits, B. (2014). Third edition. The Grasshopper. Canada: Broadview Press.

Tekiner, D. (2006). Formalist art criticism and the politics of meaning. Social Justice, 33(2), 31-44.

Walther, H. (2005). Der Fuehrer. New Jersey: Chartwell Books.

Weisss, P. (1969). Sport: a philosophic inquiry. Illinois: South Illinois University Press.

Welsch, W. (2005). Sport - viewed aesthetically and even as art? From The Aesthetics of Everyday Life, Light, A \& Smith, J.M. (ed.). New York: Columbia University Press, 135-155.

Zangwill, W. (1999). Feasible aesthetic formalism. Nous, 33(4), 610-629. https://doi.org/10.1111/0029-4624.00196

Zangwill, W. (2000). In defense of moderate aestheticism. The Philosophical Quarterly, 50(201), 476-493. https://doi.org/10.1111/1467-9213.00201

\section{Copyrights}

Copyright for this article is retained by the author(s), with first publication rights granted to the journal.

This is an open-access article distributed under the terms and conditions of the Creative Commons Attribution license which permits unrestricted use, distribution, and reproduction in any medium, provided the original work is properly cited. 